\title{
Comment-Pay more, get more? The influence of pay on doctors' behaviour
}

Does the way in which doctors are paid for their work influence what they do? The article by Kristiansen and Holtedahl on page 481 suggests that it does. Norwegian doctors who were remunerated under a system that gave them $£ 31$ for home visits were more likely to do routine home visits than doctors who were paid $£ 6$ for such a visit. This is perhaps not surprising, and indeed it is reassuring that the doctors working under the two systems seemed equally likely to undertake home visits for acute illness. When the payments for night visits were increased in the United Kingdom, this did not appear to alter the underlying trend in night visiting rates, but resulted in more visits being carried out by general practitioners themselves, and fewer by deputising services. ${ }^{1}$ In neither of these examples is it clear whether patients gain from increased home visiting, and indeed in the British example it is arguable that a remuneration system which encourages doctors to work during the night could lead to impaired performance the following day.

These are examples of a number of studies which take advantage of externally driven changes in doctors' payment to study their effect on doctors' behaviour. Such studies tend to take place when there is a change in the system of remuneration, for example, from a capitation or "prepaid" system to a fee for service system. Other studies have taken advantage of sudden changes in doctors' earnings to study changes in behaviour.

Rice, ${ }^{2}$ for example, analysed the effect of changes in Medicare reimbursement rates which left some Colorado physicians earning more than previously and some less. Potential reduction in income was associated with doctors doing more surgery, more laboratory tests, and providing more intensive medical and surgical services. Hemenway ${ }^{3}$ studied doctors' behaviour in a chain of Boston ambulatory care centres that moved from paying their doctors on an hourly rate to paying the doctors bonuses related to the income which the doctors generated: there were substantial increases in laboratory tests, $x$ rays, and office visits. Likewise, on the introduction of a partial "fee for service" system of payment for Danish general practitioners, Krasnik et al reported that doctors carried out more procedures which attracted fees. ${ }^{4}$

Mechanic $^{5}$ suggested that in response to increasing workload, doctors paid on a "fee for service" basis will work longer hours, whereas those paid on a capitation basis will work faster. Rosen ${ }^{6}$ has reviewed this and other models of "physician induced demand"; and in particular the evidence that doctors set themselves a "target income", and will modify their behaviour in order to try to achieve this.

It is not clear in the examples described above what effect financially driven changes in doctors' behaviour might have on the health of their patients. It is of course possible that patients may receive unneccessary treatment when doctors' remuneration is heavily linked to carrying out specific procedures, for example, operations and investigations. Rarely has the payment mechanism of doctors been altered specifically to achieve health gain for the population.
In the United Kingdom, there is a long history of government influencing clinical practice through doctors' renumeration. For example in 1964, specific support for group practices, for improvement of premises, and for ancillary staff led to dramatic chages in British general practice which produced the structure of primary care as it exists today. However, in 1990, payments to general practitioners aimed more directly at producing health gain were introduced. These payments were for the achievement of target levels of immunisation and cervical cytology screening in practice populations, and this change has resulted in a substantial increase in these preventive activities. At the same time, payments were made to general practitioners who established "health promotion clinics". In the first 12 months of the new arrangements, most health authorities found $80 \%$ of their practices claiming for health promotion clinics, with these practices claiming an average of more than 70 clinics in the first year. ${ }^{7}$ The effectiveness of the health promotion taking place in these clinics was open to serious doubt ${ }^{8}$ and in response to a rapid increase in fees claimed, they were scrapped after two years. In their place, the UK government introduced in 1993 payments to practices which reached defined levels of population screening and action taken in respect of cardiovascular risk factors, and payments for compliance with management protocols for asthmatic and diabetic patients. It remains to be seen how doctors will respond to these incentives.

The way in which doctors behave is related, at least in part, to how they are paid. The recent UK experience in primary care was initially misguided and poorly backed by scientific evidence. However, it represents an interesting attempt to use the payment mechanism to improve the health of a nation, which may prove successful in the long run. It relies on the UK's system of health care where almost all the population is registered with a general practitioner, and which offers unique opportunities to influence the health of the population by altering the behaviour of one group of doctors.

M ROLAND

Department of General Practice, University of Manchester Medical School

1 Salisbury C. Visiting through the night. BMF 1993; 306: 762-4.

2 Rice $\mathrm{TH}$. The impact of changing Medicare reimbursement rates on physician induced demand. Medical Care 1983; 21: 803-15.

3 Hemenway D, Killen A, Cashman SB, Parks CL, Bicknell WJ. Physicians' responses to financial incentives: evidence from a for profit ambulatory care centre. N Engl F Med 1990; 322: 1059-63.

4 Krasnik A, Groenewegen PP, Pedersen PA, et al. Changing remuneration systems: effect on activity in general practice, $B M \gamma$ 1990; 300: 1698-701.

5 Mechanic D. The organisation of medical practice and practice oriens-701. among physicians in prepaid and non-prepaid primary practice orientations Care 1975; 13: 189-204.

6 Rosen B. Professional reimbursement and professional behaviour: emerging issues and research challenges. Soc Sci Med 1989; 29: 455-62.

7 National Health Service Management Executive. Health Service Indicators 1990/91. London: HMSO, 1992.

8 Morrell DC. Role of research in development of organisation and structure of general practice. BMf 1991; 302: 1313-6. 